\title{
Physical-chemical Background of the Potential Phase Transitions during Loss of Coolant Accidents in the Supercritical Water Loops of Various Generation IV Nuclear Reactor Types
}

\author{
Gábor Györke1, Attila R. Imre',2* \\ 1 Department of Energy Engineering, Faculty of Mechanical Engineering, Budapest University of Technology and Economics, \\ H-1111 Budapest, Múegyetem rkp. 3, Hungary \\ 2 Thermohydraulics Department, Atomic Energy Research, Centre for Energy Research, Hungarian Academy of Sciences (MTA), \\ H-1525 Budapest, POB 49, Hungary \\ * Corresponding author, e-mail: imreattila@energia.bme.hu
}

Received: 29 June 2018, Accepted: 08 November 2018, Published online: 18 March 2019

\begin{abstract}
Loss of coolant accidents (LOCA) are a serious type of accidents for nuclear reactors, when the integrity of the liquid-loop breaks. While in traditional pressurized water reactors, pressure drop can cause flash boiling, in Supercritical-Water Cooled reactors, the pressure drop can be terminated by processes with fast phase transition (flash boiling or steam collapse) causing pressure surge or the expansion can go smoothly to the dry steam region. Modelling the pressure drop of big and small LOCAs as isentropic and isenthalpic processes and replacing the existing reactor designs with a simplified supercritical loop, limiting temperatures for various outcomes will be given for 24.5 and $25 \mathrm{MPa}$ initial pressure. Using the proposed method, similar accidents for chemical reactors and other equipment using supercritical fluids can be also analyzed, using only physical-chemical properties of the given supercritical fluid.
\end{abstract}

Keywords

adiabatic expansion, isenthalpic expansion, steam collapse, flash boiling

\section{Introduction}

Loss of coolant accidents (LOCA) are a serious type of accidents for nuclear reactors [1]. During a LOCA, the integrity of the liquid-loop breaks, and therefore the systems can lose some working fluid, associated with pressure loss and temperature decrease. For most of the traditional nuclear reactors, where the working (and also the moderator) fluid is pressurized liquid water, in the immediate vicinity of the break, the water can produce a very fast, sometimes explosion-like boiling, the so-called "flashing" [2]. When the pressure loss is fast, this phenomenon can happen in the very initial stage of LOCA. After the flashing - or flash boiling - some steam can escape the pipes, while part of the vapour stays inside with the liquid, producing a mixed, two-phase fluid, which has drastically different physical properties than the original one-phase liquid.

Application of supercritical water as moderator and working fluid has several advantages, as well as disadvantages [3]. Due to the advantages, one of the groups for the
Generation IV. reactors are the supercritical water cooled models, where slightly different designs are often referred as Super LWR, HPLWR, etc. [4, 5], but in general, all of these types can be referred as SCWR. One of the advantages is that the supercritical fluid is in permanent onephase stage, i.e. there is no separate liquid and steam, at least not in normal working conditions. But as it has already been discussed [6], during accidents associated with fast pressure drop, phase transitions might happen even in supercritical loops. While in pressurized water reactors (PWR), accidents with pressure drops can cause only fast liquid-to-vapour phase transition (flashing), in SCWRs the reverse might be also possible (fast vapourto-liquid transition). For the latter, a similar phenomenon can be also observed - at least in theory - for PWRs, but only under special conditions. It is the so-called condensation-induced water hammer (CIWH), which can be occasionally observed in the thermal loop of PWRs or in other 
pipelines when cold water is injected into the pipes containing hot steam (for example upon flooding the pipes from the hydroaccumulators after the loss of high amount of coolants) [7, 8]. The mixture of the two phases and the subsequent cooling of the steam can lead to the sudden collapse of the vapour phase (steam pocket), causing a quick and dangerous transient (pressure surge). Although this phenomenon can be also associated with LOCA, but in PWRs, it cannot be the direct consequence of the pressure drop and it can happen only in the later stage of LOCA.

In this paper, we are going to map the conditions and show the processes where the initially supercritical water might exhibit flashing or sudden steam condensation. Big LOCAs will be approximated as reversible adiabatic expansion processes (constant entropy), while small LOCAs will be approximated as isenthalpic processes. For various SCWR designs (represented by a given working pressure and a maximal and minimal working temperature), safe temperature zones - if any - will be given, where flashing and/or CIWH-like sudden steam collapse can be avoided. Obviously the discussion is valid for all events where sudden pressure-drop can be observed, like for example blowdown, only in non-accidental cases, one might avoid the unwanted phase transitions by proper choice of the initial conditions [4].

\section{Methods}

Loss of Coolant Accidents can be caused by break of a pipe or causing some other discontinuity in the loop. LOCAs can be characterized as big, medium or small, or more accurately by giving the relative area of break (compared to the cross-section of the original pipe) in \%. It should be mentioned here, while the biggest LOCA of PWRs can reach $200 \%$ ("double-ended break"), for SCWR - or at least in some types of the SCWR - the biggest LOCA is $100 \%$, due to the special flow-geometry [9].

In our study, instead of applying various flow models, conservative estimations are applied to describe very small and very big LOCAs. For all processes, only the path of the given process will be calculated in various thermodynamic representations (like pressure-temperature, pressure-enthalpy, etc.) without giving the actual temporal description (time dependence) of the process. Small LOCAs are modelled as isenthalpic expansion, while big LOCAs are modelled as isentropic (reversible adiabatic) expansion. These assumptions are quite plausible, since slow loss of pressurized materials (like a throttling process) can be routinely approximated as isenthalpic process, while very fast expansions - which can be assumed by having a big discontinuity / break in the system in big LOCA - can be approximated as adiabatic (and in ideal case, as reversible adiabatic, i.e. isentropic) processes (like compression and expansion during sound propagation).

These assumptions would be exact only in thermally insulated systems. Although metal pipes in an SCWR cannot be considered thermally insulated, it can be assumed that for the initial period of LOCA, one can still use these approximations, because the loss of heat - within short time - can be neglected.

An additional and quite important approximation for the calculations is the use of a simple supercritical loop, instead of the real reactor design [6]. The working pressure and the maximal / minimal working temperatures used in the calculations match the values used in various real designs (see Table 1, data are taken from various references [10-14]), while internal pressure is always taken as atmospheric $(0.1 \mathrm{MPa})$. In this way, concerning various supercritical water cooled reactor designs, only the pressure and temperature ranges of the normal working conditions are considered here; all other differences (zone design, safety system, etc.) will be omitted.

In the calculation, the water is assumed to be pure. For the estimation of the properties of water, as well as for the calculation of the expansion routes, the IAPWS Equation of State were used [15], implemented into the ThermoC program and to the NIST Chemistry Webbook [16, 17].

\section{Metastable regions and fast phase transitions}

Upon the change of pressure and/or temperature from stable one phase states (pure liquid or pure, dry steam) into the direction of the other phase, phase transition line can be reached sooner or later. Going from the liquid side, reaching the equilibrium vapour pressure curve (also called as saturation curve, two-phase curve or boiling curve), one might induce boiling, while going from the vapour side, droplet condensation can be seen (Fig. 1, at the end of solid vertical arrow). These normal phase transition processes

Table 1 Inlet / outlet temperatures $\left(T_{\text {in }}\right.$ and $T_{\text {out }}$, given in $\left.{ }^{\circ} \mathrm{C}\right)$ and working pressures ( $p$, given in $\mathrm{MPa}$ ) of various supercritical water cooled reactor

designs. For two values, different spectra (thermal / mixed / fast) are considered. Data are taken from various references [10-14].

\begin{tabular}{lccccc}
\hline & Canadian & Chinese & European & Japanese & Russian \\
\hline$p$ & 25 & $25 / 25$ & 25 & $25 / 25$ & 24.5 \\
$T_{\text {in }}$ & 350 & $280 / 280$ & 280 & $290 / 280$ & 290 \\
$T_{\text {out }}$ & 625 & $500 / 510$ & 500 & $560 / 501$ & 540 \\
\hline
\end{tabular}


are relatively slow, due to the time-consuming transport of the latent heat required to fully turn liquid to steam or vice versa. On the other hand, it is possible to cross the saturation curve without inducing phase transition, especially when the change of pressure and/or temperature is fast and the water is pure. In that case, the liquid can stay liquid even by crossing the boiling line; this is a so-called metastable state, namely overheated liquid state (historically it is referred as superheated liquid state, when the metastable region is reached purely by heating the system). Obviously going farther and farther from the boiling line and being deeper and deeper in the region, where steam should exist as the stable state, the level of metastability of the liquid will be higher and higher, and finally reaches a level where the metastable liquid water has to boil immediately. This is the so-called thermodynamic stability limit. The ultimate stability limit is the liquid spinodal line (lower dotted line in Fig. 1), but usually liquid boils before reaching that limit. This kind of boiling - unlike the normal one - is very fast, like an explosion (sometimes referred as physical explosion); it can be considered as a very fast (flash) boiling. Similar phenomena (represented by horizontal arrows in Fig. 1) can be seen by cooling or pressurizing the steam above the boiling curve; in that case a sudden condensation can be seen, resembling a very fast steam pocket collapse during condensation-induced water-hammer. Metastable vapour state also has a stability line, this is represented by the upper dotted line in Fig. 1. Following both types of sudden phase transition, transient pressure waves can be

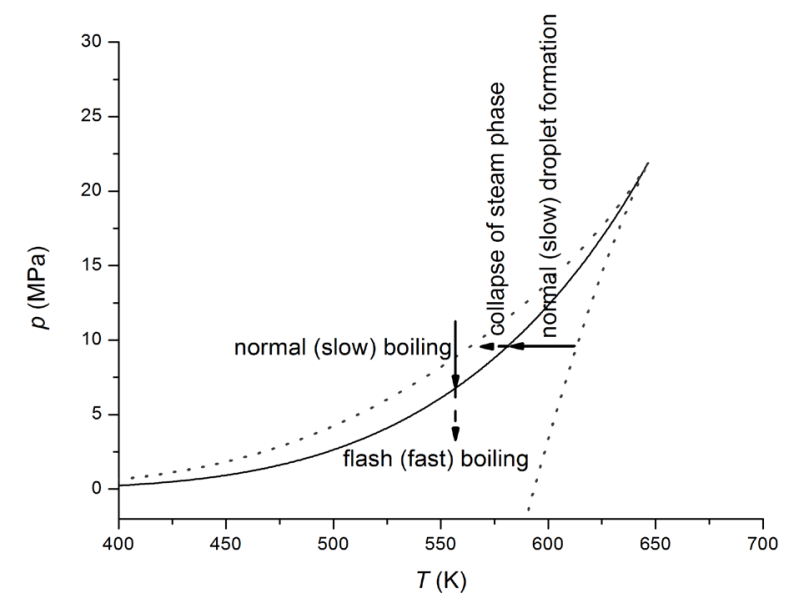

Fig. 1 Saturation curve (solid) and stability lines (dotted) of water, calculated from IAPWS equation of state. Vertical arrows represent an approach by pressure drop from stable liquid state to boiling condition

(solid) and then reaching metastable liquid conditions (dashed).

Horizontal arrows show similar process for steam, only in this case, temperature is the changing variable (cooling). expected; sometimes they can be strong enough to harm the integrity of the fluid loop (pipes), especially when the system has already been damaged and the expansion is the result of the initial damage (like pressure loss by LOCA).

Readers can find further information about metastable states and phase transitions related to these states in the following references (among others): [18-21]. It should be mentioned here, that the slight extension of the pressure scale as well as the liquid stability lines below $p=0$ value are intentional; liquids reaching metastable states by decreasing their pressure can reach negative pressure states, were the absolute scalar pressure will be smaller than zero (see for example in [18-22]), although these states are probably very rarely seen in LOCA.

As it has been shown elsewhere, adiabats - associated with very fast changes - can intrude into the metastable region [23]. In similar manner, isenthalpic expansion lines might also penetrate into the metastable region, although as being associated with slower processes, probably they can intrude less deep that adiabatic ones.

\section{Results and Discussion}

In Fig. 2, various expansion lines of pure water can be seen, calculated with ThermoC with implemented IAPWS equation of state $[16,17]$. The expansion starts from $25 \mathrm{MPa}$ (a frequently used pressure for several SCWR designs) and terminates either on the external pressure $(0.1 \mathrm{MPa})$ or by reaching the saturation curve at $p>0.1 \mathrm{MPa}$ values and penetrates into the metastable region (see the dashed extension for schematic penetration). During adiabatic expansion of liquid water or steam, the pressure drop is always associated with an inherent temperature drop (i.e. cooling caused by

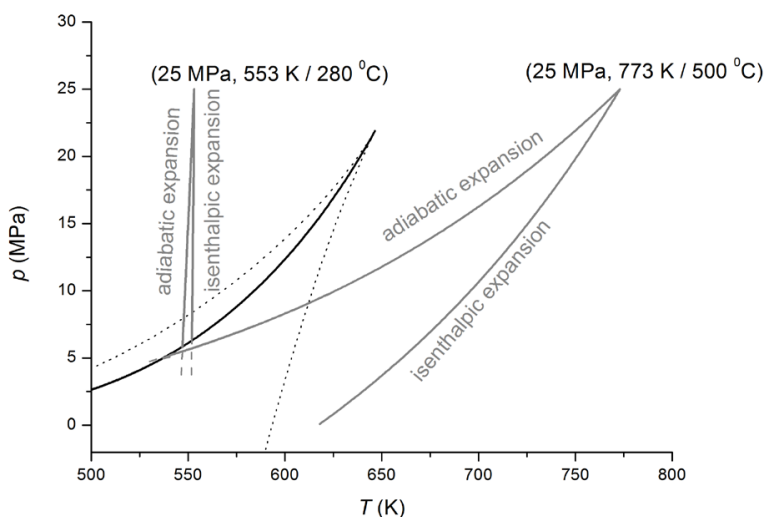

Fig. 2 Adiabatic and isenthalpic expansion lines of water starting from $25 \mathrm{MPa}, 280{ }^{\circ} \mathrm{C}$ and $25 \mathrm{MPa}, 500{ }^{\circ} \mathrm{C}$. Solid grey lines represent the expansion lines in the stable one-phase region, while dashed extension shows the potential intrusion into the metastable region. Vapour pressure line is solid black, while stability lines are shown as dotted black lines. 
the expansion). Starting from lower temperatures, expansion lines can reach the saturation curve from the liquid side; in this case, penetrating into the metastable region, flash-boiling can be seen. Starting the expansion from higher temperatures, the saturation curve will be reached from the vapour side; in this case, steam collapse can be seen. The extent of penetrations depends on various parameters and cannot be calculated for such a complex systems like a nuclear reactor, but for our purpose - to show the possibility of flash boiling or CIWH during SCWR LOCA for various SCWR designs - it is sufficient to prove the possibility of penetration itself.

The two initial conditions used for the expansions shown in Fig. 2, are taken from the normal working condition limits (inlet and outlet temperatures) of the Chinese and European SCWR designs. Other designs might use different inlet and outlet conditions, but with a few exceptions, they are close to these values (see Table 1 for the inlet / outlet temperatures and working pressures of various designs). Although the Canadian design uses heavy water $\left(\mathrm{D}_{2} \mathrm{O}\right)$ instead of light water $\left(\mathrm{H}_{2} \mathrm{O}\right)$, for the sake of completeness, it is also included in the table with approximation that causes only 2-3 K differences by using light water equation of state for the calculations.

For the expansion calculations, existing designs are replaced with a simplified supercritical loop [6]. The pressure of the fluid is always considered constant (24.5 MPa or $25 \mathrm{MPa}$ ), while the temperature changes between maximal and minimal working temperatures of the actual designs (see Table 1). The loop is shown in Fig. 3.

Expansion lines for isenthalpic processes (small LOCA) can be seen in $p$ - $h$ (pressure vs. specific enthalpy) diagram (Fig. 4 (a)) and for reversible adiabatic (isentropic) expansions in $p$-s (pressure vs. specific entropy) diagram (Fig. 4 (b)). For the sake of better visibility, the pressure

(a)

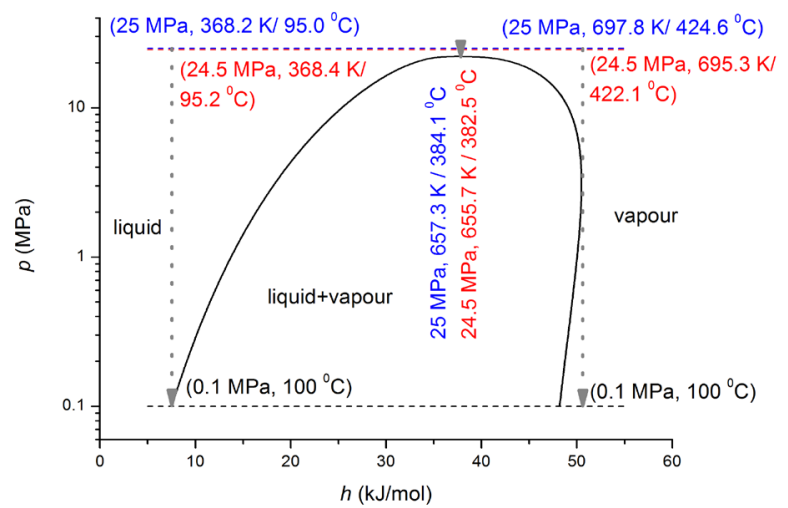

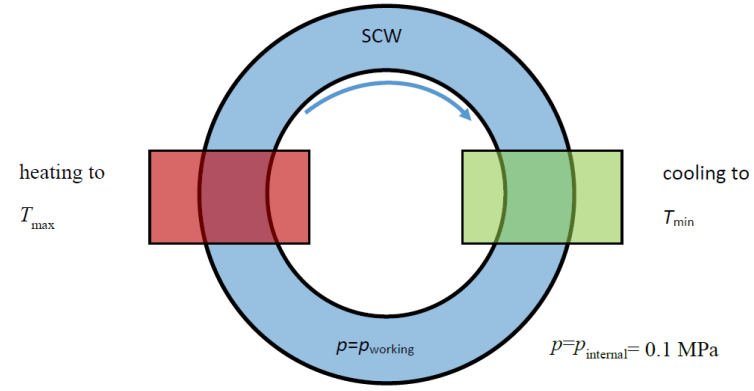

Fig. 3 Simplified supercritical loop used in LOCA-calculations. The pressure of the fluid is always considered constant, while the temperature changes between maximal and minimal working temperatures (see Table 1). The direction of flow is marked by an arrow.

axes are scaled logarithmically. Adiabats or isenthalpic lines starting at the given maximal pressure and between the maximal and minimal temperatures have to reach the two-phase region, before reaching $0.1 \mathrm{MPa}$, which is the deepest possible pressure for the expansion lines.

As it can be seen in Fig. 4 (a), concerning 24.5 MPa initial pressure (red marks), the isenthalpic expansion lines (represented by the green arrows) starting at initial temperatures between $368.4 \mathrm{~K}\left(95.2^{\circ} \mathrm{C}\right)$ and $655.7 \mathrm{~K}\left(382.5^{\circ} \mathrm{C}\right)$ can reach the saturation curve from the liquid side (potential flash-boiling), while starting at initial temperatures between $655.7 \mathrm{~K}\left(382.5^{\circ} \mathrm{C}\right)$ and $695.3 \mathrm{~K}\left(422.1^{\circ} \mathrm{C}\right)$, the saturation curve will be reached from the vapour side (potential steam collapse). Isenthalpic expansion lines starting at temperatures above $695.3 \mathrm{~K}\left(422.1^{\circ} \mathrm{C}\right)$ can avoid the saturation curve completely and they will be terminated in the dry steam region at ambient pressure; in this case, (small) LOCA will not be finished by fast phase transition, only normal steam expansion can be seen.

Concerning the same, small LOCA situation, but starting the expansion from $25 \mathrm{MPa}$ (blue marks in Fig. 4 (a)),

(b)

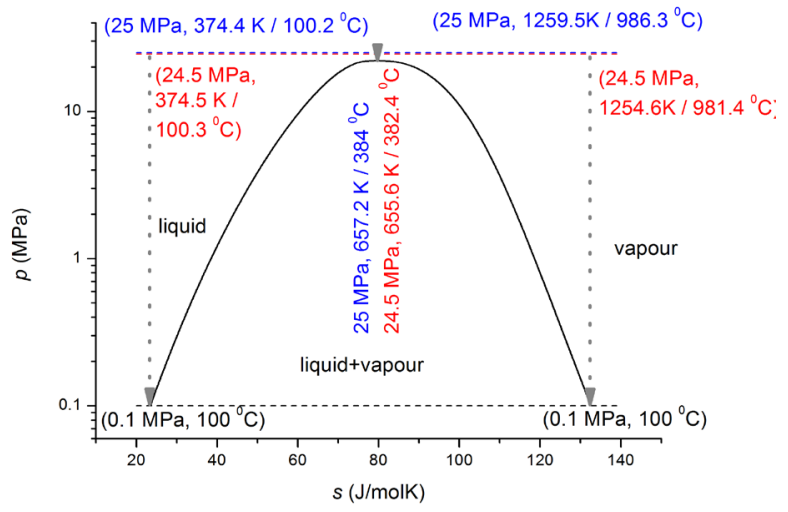

Fig. 4 Limiting isenthalpic (a) and ideal adiabatic (b) expansion lines to $0.1 \mathrm{MPa}$, showing the final phase at the expansion for $25 \mathrm{MPa}$ (blue) and 24.5 MPa (red) initial pressures. Temperatures separating various zones are given in ${ }^{\circ} \mathrm{C}$ and $\mathrm{K}$. Solid black lines are the two-phase boundary curves. 
the temperatures shown above will be slightly different. The isenthalpic expansion lines starting at initial temperatures between $368.2 \mathrm{~K}\left(95.0{ }^{\circ} \mathrm{C}\right)$ and $657.3 \mathrm{~K}\left(384.1^{\circ} \mathrm{C}\right)$ can reach the saturation curve from the liquid side (potential flash-boiling), while starting at initial temperatures between $657.3 \mathrm{~K}\left(384.1^{\circ} \mathrm{C}\right)$ and $697.8 \mathrm{~K}\left(424.6^{\circ} \mathrm{C}\right)$, the saturation curve will be reached from the vapour side (potential steam collapse). Isenthalpic expansion lines starting at temperatures above $697.8 \mathrm{~K}\left(424.6^{\circ} \mathrm{C}\right)$ can avoid the saturation curve completely and they will be terminated in the dry steam region at ambient pressure.

For big LOCA, modelled as isentropic expansion, potential processes are shown in Fig. 4 (b). For processes starting from 24.5 $\mathrm{MPa}$ (red), the expansion lines starting at initial temperatures between $374.5 \mathrm{~K}\left(100.3{ }^{\circ} \mathrm{C}\right)$ and $655.6 \mathrm{~K}$ $\left(382.4^{\circ} \mathrm{C}\right)$ can reach the saturation curve from the liquid side (potential flash-boiling), while starting at initial temperatures between $655.6 \mathrm{~K}\left(382.4^{\circ} \mathrm{C}\right)$ and $1254.4 \mathrm{~K}\left(981.4{ }^{\circ} \mathrm{C}\right)$, the saturation curve will be reached from the vapour side (potential steam collapse). In this case - due to the different characteristics of entropy and enthalpy curves - the saturation curve cannot be avoided, although for expansion lines starting above temperatures $1254.4 \mathrm{~K}\left(981.4{ }^{\circ} \mathrm{C}\right)$, the saturation line will not be reached until ambient pressure $(0.1$ $\mathrm{MPa}$ ), therefore at higher temperatures, expansion lines will be terminated in the dry steam region.

Concerning the big LOCA, starting at $25 \mathrm{MPa}$ (blue in Fig. 4 (b)), the temperatures are shown above change slightly. Expansion lines starting at initial temperatures between $374.4 \mathrm{~K}\left(100.2^{\circ} \mathrm{C}\right)$ and $657.2 \mathrm{~K}\left(384.0{ }^{\circ} \mathrm{C}\right)$ can reach the saturation curve from the liquid side (potential flash-boiling), while starting at initial temperatures between $657.2 \mathrm{~K}\left(384.0^{\circ} \mathrm{C}\right)$ and $1259.5 \mathrm{~K}\left(986.3{ }^{\circ} \mathrm{C}\right)$, the saturation curve will be reached from the vapour side (potential steam collapse). In this case for expansion lines starting above temperatures $1259.5 \mathrm{~K}\left(986.3{ }^{\circ} \mathrm{C}\right)$, the saturation line will not be reached until ambient pressure $(0.1 \mathrm{MPa})$, therefore at higher temperatures, expansion processes will be terminated in the dry steam region.

Temperature ranges for various types of expansions terminated by various processes, including ones with sudden phase transition (flash or steam collapse) or ended without phase transition (terminated in the single-phase dry-steam region) are summed in Fig. 5 (a) for $25 \mathrm{MPa}$ initial pressure and in Fig. 5 (b) for $24.5 \mathrm{MPa}$ initial pressure. Working temperature ranges for various designs are also shown.

It should be mentioned that the "medium" temperature, separating expansion lines going to the liquid and vapour side are one of the many Widom-points / lines, marking the liquid-like, vapour-like and anomalous parts of the supercritical region [24-27].

Concerning the results shown in Figs. 4 and 5, one can see that for all concepts (either working on $25 \mathrm{MPa}$ or on 24.5 $\mathrm{MPa}$ ), pressure drops to atmospheric pressure during big LOCAs (modelled as ideal adiabatic processes) always lead to a sudden phase transition; flashing, when it happens at the low-temperature part of the system and steam collapse for the higher temperature parts. Concerning small LOCA, when the pressure drop happens at the high-temperature part of the loop, it is possible to change the originally vapour-like supercritical fluid to dry steam, without having any sudden phase transition. In this case, one can say that having a small
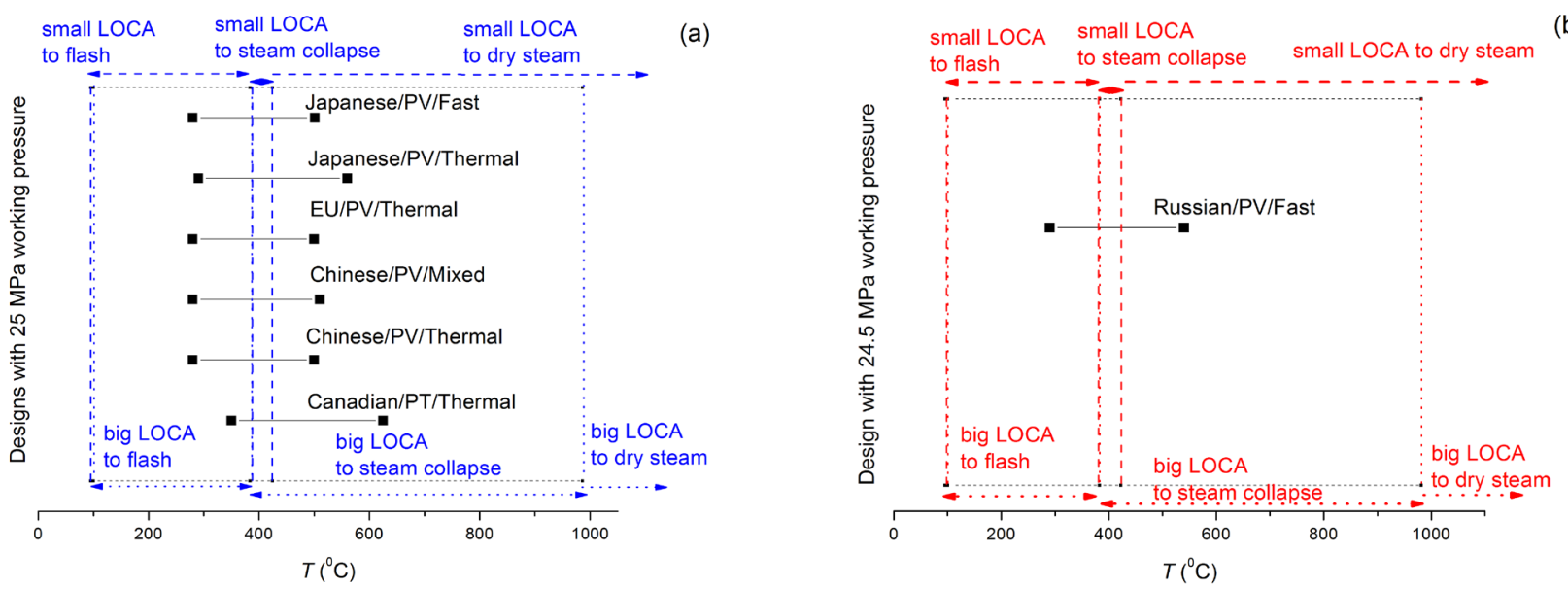

(b)

Fig. 5 Temperature ranges for various types of expansions, starting from supercritical state and causing sudden phase transition (flash or steam collapse) or no phase transition (terminated in the single-phase dry-steam region). Limits for SCWR models with $25 \mathrm{MPa}$ working pressure (a) or 24.5 MPa (b) shown separately. Working temperature of various reactor designs are also shown; different types are marked by their origins, their types (pressurized tubes or pressurized vessel as PT or PV) and by their spectra. 
LOCA in the supercritical loop, where the initial fluid temperature is above $422.1{ }^{\circ} \mathrm{C}$ (at $24.5 \mathrm{MPa}$ ) or $424.6^{\circ} \mathrm{C}$ (at 25 $\mathrm{MPa}$ ), sudden phase transitions - and the pressure transient, following them - can be avoided. One should mention that the loop representing the Canadian design (25 MPa, 350$625^{\circ} \mathrm{C}$ ) has the "widest" safe region for small LOCA and also this is the one, where small LOCA can cause flash boiling only in a very limited temperature range.

It can be seen that such temperatures as the one predicted for system to have safe region for adiabatic expansion (big LOCA) are too high for different alloys used in PWRs or intended to be used in SCWRs [28]. Although the temperature is still below the values where thermal dissociation of water to hydrogen or oxygen becomes significant [29], theoretically, reactors can work on such a high temperature (assuming to have been made from proper materials). Also, these calculations might be useful for the design the cooling loop of future fusion reactors, where the temperature might reach these values.

Although only temperature limits are given, upon stationary flow, a location-temperature map can be constructed for real or model loops. We do not have the proper tools for doing that, but we can assume that for all design, the high-temperature part of the liquid loop should be in the vicinity of the zone; having big LOCA with pressure drop to $0.1 \mathrm{MPa}$ would shift the initially homogeneous supercritical fluid (already quite vapour-like in this condition) [26] to the steam-region, then - by reaching the saturation condition - fast steam-collapse would finish the expansion. For small LOCA - also in the region of reactor zone, where temperatures are close to the maximal working temperature - the supercritical fluid (already quite vapour-like even in the supercritical condition) would expand to dry steam region without having any fast phase transition and the subsequent pressure surge. In the outermost, coldest part of the loop (close to the heat exchanger) both small and big LOCA could cause flash boiling.

\section{Conclusions}

For supercritical water used as working / moderator fluid for reactors, one of the advantage - compared to pressurized water - that under normal conditions, phase

\section{References}

[1] Chuanxin, P., Wenbin, Z., Bingde, C., Changhua, N., Yanping, H. "Research and Evaluation for Passive Safety System in Low Pressure Reactor", Science and Technology of Nuclear Installations, 2015, Article ID 179235, 2015 https://doi.org/10.1155/2015/179235 transitions can be avoided. It has already been shown that although it is true for normal conditions, by accidents causing pressure loss, sudden phase transitions like flash boiling or steam collapse can be induced [6]. This differs from the pressurized water case, where only flash boiling can be caused directly by these kinds of accidents.

In this paper, various SCWR designs were analyszed, comparing their behavior upon an idealized small LOCA (isenthalpic expansion) and big LOCA (isentropic expansion). Replacing the actual reactor designs with a simplified fluid loop, we were able to give the temperature ranges, where sudden phase transitions (flash boiling or steam collapse, followed by pressure surge) can be caused by the various LOCAs; also safe temperature regions, where these phase transitions can be avoided are estimated. Although only temperature limits are given, upon stationary flow, a location-temperature map can be constructed for real or model loops. In this way, these results can be used for the better design of safety features of various SCWR models.

One has to realize that the existence of the two phenomena described here (steam collapse and flash boiling) is independent from the layout of the reactor, therefore real geometries should be taken only for quantitative studies. The flash and steam collapse during LOCA in supercritical loops existence is caused solely by the special physical-chemical properties of the subcritical, supercritical and metastable water.

Also, using similar method, accidents connected with pressure loss in various kinds of facilities (extraction columns, supercritical water oxidation reactors, etc.) can be analyzed, using the physical-chemical properties of the given supercritical fluid.

\section{Acknowledgement}

This work was performed in the frame of FIEK_16-12016-0007 project, implemented with the support provided from the National Research, Development and Innovation Fund of Hungary, financed under the FIEK_16 funding scheme. Partial financial supports of the Hungarian National Innovation Office grant (NKFIH, grant No. K116375) is also acknowledged.

[2] Wang, J., Guo, X., Yu, S., Cai, B., Sun, Z., Yan, C. "Study on the Behaviors of a Conceptual Passive Containment Cooling System", Science and Technology of Nuclear Installations, 2014, Article ID 358365, 2014 https://doi.org/10.1155/2014/358365 
[3] Pioro, I. L., Duffey, R. B. "Heat Transfer and Hydraulic Resistance at Supercritical Pressure in Power Engineering Applications", ASME, New York, USA, 2007.

https://doi.org/10.1115/1.802523

[4] Ishiwatari, Y., Oka, Y., Koshizuka, S. "Safety of the Super LWR", Nuclear Engineering and Technology, 39(4), pp. 257-272, 2007. https://doi.org/10.5516/NET.2007.39.4.257

[5] Fischer, K., Schulenberg, T., Laurien, E. "Design of a supercritical water-cooled reactor with a three-pass core arrangement", Nuclear Engineering and Design, 239(4), pp. 800-812, 2009.

https://doi.org/10.1016/j.nucengdes.2008.12.019

[6] Imre, A. R., Barna, I. F., Ézsöl, G., Házi, G., Kraska, T. "Theoretical study of flashing and water hammer in a supercritical water cycle during pressure drop", Nuclear Engineering and Design, 240(6), pp. 1569-1574, 2010.

https://doi.org/10.1016/j.nucengdes.2010.03.008

[7] Barten, W., Jasiulevicius, A., Manera, A., Macian-Juan, R., Zerkak, O. "Analysis of the capability of system codes to model cavitation water hammers: Simulation of UMSICHT water hammer experiments with TRACE and RELAP5", Nuclear Engineering and Design, 238(4), pp. 1129-1145, 2008.

https://doi.org/10.1016/j.nucengdes.2007.10.004

[8] Costa, O., Tiselj, I., Cizelj, L. "Depressurization of Vertical Pipe with Temperature Gradient Modeled with WAHA Code", Science and Technology of Nuclear Installations, 2012, Article ID 951923, 2012.

https://doi.org/10.1155/2012/951923

[9] Ishiwatari, Y., Oka, Y., Koshizuka, S., Liu, J. "LOCA Analysis of Super LWR", Journal of Nuclear Science and Technology, 43(3), pp. 231-241, 2006. https://doi.org/10.1080/18811248.2006.9711085

[10] Schulenberg, T., Leung, L. "8 - Super-critical water-cooled reactors", In: Pioro, I. L. (ed.) Handbook of Generation IV Nuclear Reactors, Woodhead Publishing Series in Energy, 1st ed., Woodhead Publishing, Duxford, UK, 2016, pp. 189-220. https://doi.org/10.1016/B978-0-08-100149-3.00008-2

[11] Ryzhov, S. B., Mohov, V. A., Nikitenko, M. P., Kirillov, P. I., Chetverikov, A. E., Makhin, V. M., Churkin, A. N., Glebov, A. P. "Concept of A Single-Circuit RP with Vessel Type Supercritical Water-Cooled Reactor", In: $5^{\text {th }}$ International Symposium on Supercritical Water-Cooled Reactors, Vancouver, Canada, 2011, pp. $1-13$.

[12] IAEA "Status Report - Chinese Supercritical Water-Cooled Reactor (CSR1000)", [pdf] IAEA Advanced Reactor Information System (ARIS) Database, 2015. Available at: https://aris.iaea.org/ PDF/CSR1000.pdf [Accessed: 29 June 2018]

[13] Yamada, K., Sakurai, S., Asanuma, Y., Hamazaki, R., Ishiwatari, Y., Kitoh, K. "Overview of the Japanese SCWR Concept Developed under the GIF Collaboration", In: $5^{\text {th }}$ International Symposium on Supercritical Water-Cooled Reactors, Vancouver, Canada, 2011, pp. 1-14.

[14] Leung, L. "Super-Critical Water-Cooled Reactors", [pdf] Gen IV International Forum(GIF), Webinar Series 7, 2017. Available at: https:// www.gen-4.org/gif/upload/docs/application/pdf/2017-04/geniv_ template_laurence_leung_final.pdf [Accessed: 28 March 2017]
[15] Wagner, W., Pruß, A. "The IAPWS Formulation 1995 for the Thermodynamic Properties of Ordinary Water Substance for General and Scientific Use", Journal of Physical and Chemical Reference Data, 31(2), pp. 387-535, 2002.

https://doi.org/10.1063/1.1461829

[16] NIST (National Institute of Standards and Technology, U.S. Department of Commerce) "NIST Chemistry WebBook, SRD 69", [online] Available at: http://webbook.nist.gov/ [Accessed: 29 June 2018]

[17] Group of Deiters, U. K. "ThermoC", [online] Available at: http:// thermoc.uni-koeln.de/ [Accessed: 28 June 2018]

[18] Skripov, V. P. "Metastable Liquids",Halsted Press, John Wiley \& Sons, New York, USA, 1974.

[19] Trevena, D. H. "Cavitation and Tension in Liquids", 1st ed., Adam Hilger, Bristol, UK, 1987.

[20] Debenedetti, P. G. "Metastable Liquids: Concepts and Principles", 1st ed., Princeton University Press, Princeton, USA, 1996.

[21] Imre, A. R., Maris, H. J., Williams, P. R. (eds.) "Liquids Under Negative Pressure", NATO Science Series II, 1st ed., Kluwer Academic Publishers, Dordrecht, The Netherlands, 2002.

[22] Imre, A. R. "On the existence of negative pressure states", physica status solidi (b) - basic solid state physics, 244(3), pp. 893899, 2007.

https://doi.org/10.1002/pssb.200572708

[23] Imre, A. R., Quiñones-Cisneros, S. E., Deiters, U. K. "Adiabatic Processes in the Liquid-Vapor Two-Phase Region. 1. Pure Fluids", Industrial \& Engineering Chemistry Research, 53(34), pp. 1352913542, 2014.

https://doi.org/10.1021/ie5022688

[24] Xu, L., Kumar, P., Buldyrev, S. V., Chen, S.-H., Poole, P. H., Sciortino, F., Stanley, H. E. "Relation between the Widom line and the dynamic crossover in systems with a liquid-liquid phase transition", Proceedings of the National Academy of Sciences of the United States of America (PNAS), 102(46), pp. 16558-16562, 2005. https://doi.org/10.1073/pnas.0507870102

[25] Brazhkin, V. V., Ryzhov, V. N. "Van der Waals supercritical fluid: Exact formulas for special lines", The Journal of Chemical Physics, 135, 084503, 2011. https://doi.org/10.1063/1.3627231

[26] Imre, A. R., Deiters, U. K., Kraska, T., Tiselj, I. "The pseudocritical regions for supercritical water", Nuclear Engineering and Design, 252, pp. 179-183, 2012. https://doi.org/10.1016/j.nucengdes.2012.07.007

[27] Banuti, D. T. "Crossing the Widom-line - Supercritical pseudo-boiling", The Journal of Supercritical Fluids, 98, pp. 12-16, 2015. https://doi.org/10.1016/j.supflu.2014.12.019

[28] Ehrlich, K., Konys, J., Heikinheimo, L. "Materials for high performance light water reactors", Journal of Nuclear Materials, 327(23), pp. 140-147, 2004. https://doi.org/10.1016/j.jnucmat.2004.01.020

[29] Lede, J., Lapicque, F., Villermaux, J., Gales, B., Ounalli, A., Baumard, J. F., Anthony, A. M. "Production of hydrogen by direct thermal decomposition of water: Preliminary investigations", International Journal of Hydrogen Energy, 7(12), pp. 939-950, 1982. https://oi.org/10.1016/0360-3199(82)90162-8 